\title{
A case report of Chinese brothers with inherited $M E C P 2$-containing duplication: autism and intellectual disability, but not seizures or respiratory infections
}

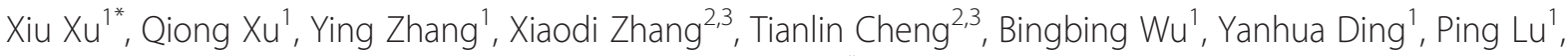 \\ Jingjing Zheng ${ }^{2,3}$, Min Zhang ${ }^{2}$, Zilong Qiu $^{2}$ and Xiang $Y u^{2 *}$
}

\begin{abstract}
Background: Autistic spectrum disorders (ASDs) are a family of neurodevelopmental disorders with strong genetic components. Recent studies have shown that copy number variations in dosage sensitive genes can contribute significantly to these disorders. One such gene is the transcription factor MECP2, whose loss of function in females results in Rett syndrome, while its duplication in males results in developmental delay and autism.

Case presentation: Here, we identified a Chinese family with two brothers both inheriting a 2.2 Mb MECP2containing duplication $(151,369,305$ - 153,589,577) from their mother. In addition, both brothers also had a $213.7 \mathrm{~kb}$ duplication on Chromosome 2, inherited from their father. The older brother also carried a $48.4 \mathrm{~kb}$ duplication on Chromosome 2 inherited from the mother, and a $8.2 \mathrm{~kb}$ deletion at $11 \mathrm{q} 13.5$ inherited from the father. Based on the published literature, MECP2 is the most autism-associated gene among the identified CNVs. Consistently, the boys displayed clinical features in common with other patients carrying MECP2 duplications, including intellectual disability, autism, lack of speech, slight hypotonia and unsteadiness of movement. They also had slight dysmorphic features including a depressed nose bridge, large ears and midface hypoplasia. Interestingly, they did not exhibit other clinical features commonly observed in American-European patients with MECP2 duplication, including recurrent respiratory infections and epilepsy.

Conclusions: To our knowledge, this is the first identification and characterization of Chinese Han patients with MECP2-containing duplications. Further cases are required to determine if the above described clinical differences are due to individual variations or related to the genetic background of the patients.
\end{abstract}

Keywords: MECP2, Autism, ASD, CNV, Chinese patients

\section{Background}

Autism spectrum disorders (ASDs) are neurodevelopmental disorders with complex etiology and strong genetic basis, characterized by impaired communication, reduced social interaction, and stereotyped and/or repetitive behavior [1-4]. Over the past decade, an emergent

\footnotetext{
* Correspondence: xuxiu@shmu.edu.cn; yuxiang@ion.ac.cn

'Department of Child Healthcare, Children's Hospital of Fudan University, Shanghai, China

${ }^{2}$ Institute of Neuroscience and State Key Laboratory of Neuroscience, Shanghai Institutes for Biological Sciences, Chinese Academy of Sciences, Shanghai, China

Full list of author information is available at the end of the article
}

feature regarding the genetics of ASD is the importance of gene dosage, where both loss and gain of function of a gene can result in autistic phenotypes [4,5]. A prominent example is the Methyl-CpG-binding Protein 2 gene (MECP2; MIM: 300005), located at Xq28. Loss of function of one copy of MECP2 leads to Rett syndrome (RTT; MIM 312750), a progressive neurodevelopmental disorder characterized by loss of motor skills and communication abilities, as well as stereotypic hand movements and other autistic features, occurring in 1:10,000 girls [6-9]. More recently, duplication of the MECP2 gene has been found in boys with developmental delay, 
intellectual disability and/or autism in a series of studies [10-28]. Core features of the syndrome included infantile hypotonia, mild dysmorphic features, developmental delay, intellectual disability, abnormal movement and absent to minimal speech. Although not all studies examined autistic characteristics, when the examinations were carried out, autistic phenotypes were prominent among patients with $M E C P 2$ duplication [15,21,23,29]. In fact, of 8 boys evaluated using the Autism Diagnostic Observation Schedule (ADOS) in one study, 7 (88\%) exceeded the cutoff score for autism, while the remaining one exceeded the score for ASD [23]. Thus altering the gene dosage of $M E C P 2$ by both deletion and duplication can generate autistic phenotypes. Corroborating these clinical findings, similarities in phenotypes, including autistic features, were observed both in mouse models of MECP2 deletions and duplications [30-34].

Whether $M E C P 2$ duplication is a cause of intellectual disability and/or autism in the Chinese Han population is unknown. A previous study screening 82 Chinese Han boys diagnosed with autism using real-time quantitative polymerase chain reaction (qPCR) failed to identify deletions or duplications in MECP2 [35]. Since the sample size was small, the question of whether MECP2 duplication is present in Chinese patients diagnosed with autism required further study. Here, we report two brothers diagnosed with autistic disorder carrying duplication in $M E C P 2$, inherited from their mother. Detailed examination, medical history inquiry and characterization by ADOS showed that these boys shared many characteristics with previously reported patients carrying duplication encompassing the $M E C P 2$ gene [10-28], including autism, intellectual disability, hypotonia and mild dysmorphic features, but not recurrent respiratory infections or epilepsy. Genome-wide CNV scan using Agilent $1 \mathrm{M}$ comparative genomic hybridization (CGH) microarray showed that both brothers carried a $2.22 \mathrm{Mb}$ MECP2-duplication containing $\mathrm{CNV}$, inherited from their mother. To our knowledge, this is the first report and characterization of MECP2 duplication patients from the Chinese Han population.

\section{Case presentation}

In a screen for CNVs in MECP2 carried out for children diagnosed with ASD at the Children's Hospital of Fudan University, 53 unrelated male subjects diagnosed with ASD using DSM-IV (average age at first diagnosis: $4.15 \pm 0.27$ years) were tested. One boy (P01A) was identified with a MECP2 duplication. This patient also had an older brother with intellectual disability and no speech. The patient, his older brother and both parents were then all assayed for CNVs in MECP2 using an Accucopy kit, a multiplex competitive amplificationbased method (Genesky Biotechnologies Inc., Shanghai, China, see Additional file 1 for details) [36]. The older brother (P01B) was found to have two copies of MECP2, the father (P01C) had a single copy, while the mother (P01D) carried three copies (Figure 1A, B). Control males and females carried one or two copies of $M E C P 2$, respectively, as expected (Figure 1B). These results, further confirmed using standard real-time qPCR (Figure 1C), showed that both brothers carried MECP2 duplication inherited from the mother.

\section{Clinical summary}

Detailed clinical data was gathered from the family. The pedigree is shown in Figure 1A. A girl (G2 P2), born between the two brothers, was born prematurely at 30 weeks, likely because the mother was startled. She died one month after birth. It was noted that she fed very poorly, although her body weight did increase slightly. On the day before she died, she did not feed at all. The cause of death was unknown, as no medical examinations were carried out. It is possible that she also carried the $M E C P 2$-containing duplication (no DNA sample available). Although DNA from other members of the mother's family could not be obtained, the pedigree showed that the mother was the youngest of 5 children, with 2 healthy brothers, and one
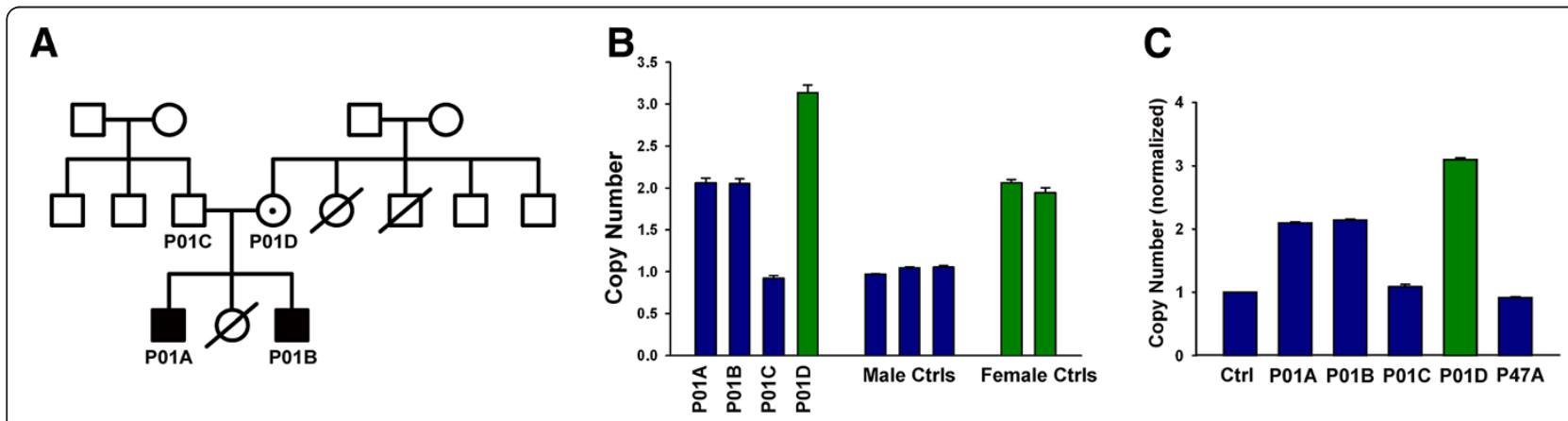

Figure 1 Identification of two brothers with inherited MECP2 duplication in Chinese autism patients. A. Pedigree of family P01, standard pedigree symbols are used. B. CNV screening using Accucopy kit for all members of family P01. C. Confirmation of results using real-time qPCR. P47A is a boy with normal MECP2 gene dosage. Males are represented by blue bars, and females by green bars. Error bars represent s.e.m. 
brother and one sister who died at a young age. The healthy brothers already have grandchildren, and both they and their progeny have no significant health or psychological issues. The older sister died before P01D was born, likely from an accident. The other brother died shortly after birth, for unknown causes. The mother of P01D is over eighty years old, of good health, apart from high blood pressure, and has normal intellectual and social abilities.

\section{Patient 01A}

Patient 01A (G3 P3 L2) was born at full-term to healthy, nonconsanguineous parents following an uneventful birth, at a birth weight of $3400 \mathrm{~g}$. He showed general developmental delay and was able to walk at the age of 20 months. When examined at the age of 9 years and 5 months, he walked and ran slightly unsteadily and could not jump with both feet off the ground. He was in the normal height range when compared to children of his age, but was slightly slender. In terms of facial features, he had large ears and a depressed nasal bridge. He was slightly hypotonic, but had no history of respiratory infections, has not undergone operations or major medical treatments and has had no seizures or epilepsy. He had no sleep disturbances, but was often constipated. He occasionally got a cold, but was not ill very often. He was hospitalized once at the age of a few months. At the age of 3-4 years, he generated a couple of words, including "mama" and "tea". Currently, he could only say "mama" and had passive understanding of simple sentences as spoken by his mother, but no other language or echolalia. He could eat a pear by himself, but needed to be fed by his mother for meals, due to difficulty holding a spoon. He occasionally ran around with other children, but could not engage in interactive play. He got very anxious when encountering strangers or when entering a new environment. When happy, he clapped his hands.

Cognitive/developmental evaluation using the Bayley Scales of Infant Development-3 [37] showed that he had cognitive and language skills, as well as motor skills well below that for his age (Table 1). This patient, who was diagnosed with autism using DSM-IV [38] at 4 years and 11 months, had an ADOS score [39] (Table 1) of 20 at the time of this examination (9 years and 5 months), well above the cutoff for autistic disorder.

\section{Patient 01B}

Patient 01B (G1 P1), the older brother of patient 01A, was 18 years old at the time of examination. He was of normal height and weight when compared to his peers. He had mild dysmorphic features including a depressed nasal bridge and midface hypoplasia. He had no history of respiratory infections or other major medical treatments and no history of seizures or epilepsy. He has not been hospitalized, and is otherwise healthy apart from an occasional cold. A previous computed tomography (CT) scan showed no obvious abnormalities. He learnt to walk at 20 months and currently walked and ran slightly unsteadily. He liked to walk on his toes, but could not jump with both feet off the floor. He had no language, but could passively understand simple phrases as spoken by his mother. He was able to eat by himself, and stayed in his room alone at all times other than

Table 1 Quantification of developmental, cognitive and autism phenotypes of MECP2 duplication-containing patients

\begin{tabular}{|c|c|c|}
\hline Subject & P01A & P01B \\
\hline Age at examination & 9 years 5 months & 18 years \\
\hline \multicolumn{3}{|l|}{ Bayley Scales of Infant Development-3 } \\
\hline Developmental age & 9 months & 6 months \\
\hline Receptive language & 15 months & 11 months \\
\hline Expressive language & 6 months & 5 months \\
\hline Fine motor & 15 months & 12 months \\
\hline Gross motor & 15 months & 15 months \\
\hline \multicolumn{3}{|l|}{ Weschler Intelligence Scale } \\
\hline Verbal IQ & $<40$ & $<36$ \\
\hline Performance IQ & $<40$ & $<14$ \\
\hline Full Scale IQ & $<40$ & $<24$ \\
\hline \multicolumn{3}{|l|}{ Autism Diagnostic Observation Schedule (ADOS) scores } \\
\hline ADOS communication score & 6 & 5 \\
\hline \multicolumn{3}{|l|}{ (cutoff score for autism is $\geq 4$ ) } \\
\hline ADOS social interaction score & 14 & 12 \\
\hline \multicolumn{3}{|l|}{ (cutoff score for autism is $\geq 7$ ) } \\
\hline Combined ADOS score (cutoff score for autism is $\geq 12$ ) & 20 & 17 \\
\hline
\end{tabular}


meal times. He liked to look at cars on the street and was very excited by wheels. When happy, he put his hands to his mouth and laughed loudly. He flapped his hands a lot and did not engage in interaction with others, but laughed often. Although this patient was 18 years at the time of examination, his cognitive, language and motor skills were in the range of 6 to 15 months as measured by Bayley Scales of Infant Development-3 [37] (Table 1). His ADOS score of 17 [39] was well above the cutoff for autistic disorder (Table 1).

\section{Parents of the patients P01A and P01B}

Since previous publications have shown that female carriers of $M E C P 2$ duplications had psychiatric symptoms, the mother of the patients (P01D) completed a Symptom Checklist-90 [40,41], and both parents completed the Wechsler Adult Intelligence Scale-Revised [42,43] and the Broad Autism Phenotype Questionnaire (BAPQ) [44]. Both parents scored in the normal range on the Wechsler Intelligence Scale (Table 2). In terms of the broad autism phenotype, both parents scored slightly higher than average, with the mother scoring further away from the cutoff score than the father (Table 2). Consistent with a previous publication [23], the mother of the patients, who also carried the MECP2-containing duplication, had slightly higher scores in somatization, depression, anxiety and psychoticism on completing Symptom Checklist-90 [40,41] and reported sleep disturbances. She reported no other healthy issues, and has not had any miscarriages.

Determination of the precise duplication interval by aCGH To determine the precise size of the MECP2 duplication and to assay if additional CNVs are present in this family, Agilent SurePrint G3 Human CGH Microarray $1 \mathrm{x} 1 \mathrm{M}$ was used to assay the entire genome of all four members of the family (performed by Shanghai Biotechnology Corporation, Shanghai, China; see Additional file 1 for details). The MECP2 containing duplication $(151,369,305$ - 153,589,577) was found to be $2.22 \mathrm{Mb}$, including a large number of genes other than $M E C P 2$ (Figure 2). The duplicated region, starting with GABRA3 and ending with FLNA, is the same in the brothers and their mother, consistent with both brothers inheriting the CNV from their mother.

Both Patients 01A and 01B also had a $213.7 \mathrm{~kb}$ duplication on Chromosome 2, inherited from their father. This region contained the genes PFN4, LOC375190, C2orf84 and ITSN2. None of these genes have been shown to be associated with autism, and furthermore, since the father is a healthy, normal adult, this $\mathrm{CNV}$ is unlikely to be disease-causing by itself. Patient 01A had no other CNVs. Patient 01B had a $48.4 \mathrm{~kb}$ duplication on Chromosome 2, containing no known genes, inherited from the mother, and a small deletion $(8.2 \mathrm{~kb})$ at 11q13.5, containing GDPD4, inherited from his father. In a previous report [45], loss of GDPD4 was found as a low frequency de novo CNV in autism patients (3 autism from 1683 analyzed) but not in normal controls. The relationship of GDPD4 to autism is otherwise unknown. In our study, since the GDPD4-containing CNV in Patient $01 \mathrm{~B}$ is inherited from a healthy parent, it is unlikely to be disease-causing by itself.

Since, based on the existing literature, the other CNVs found in Patients P01A and P01B are unlikely to be the main cause of the patients' phenotypes, our whole genome $\mathrm{CNV}$ results provided further evidence that the main genetic abnormality in patients P01A and $\mathrm{P} 01 \mathrm{~B}$ is their $M E C P 2$-containing duplication, inherited from the mother. The other CNVs could also, in principle, contribute to the patients' phenotypes in the background of the MECP2-containing duplication. As the $M E C P 2$-containing duplication region is relatively large, we also examined whether other genes in the duplicated region could contribute to the phenotype.

Table 2 Clinical summary of the parents of MECP2 duplication-containing patients

\begin{tabular}{|c|c|c|}
\hline Subject & Father (P01C) & Mother (P01D) \\
\hline \multicolumn{3}{|c|}{ Wechsler Adult Intelligence Scale-Revised } \\
\hline Verbal IQ & 93 & 92 \\
\hline Performance IQ & 138 & 95 \\
\hline Full Scale IQ & 109 & 93 \\
\hline \multicolumn{3}{|c|}{ Broad Autism Phenotype Questionnaire (cutoff score in brackets) } \\
\hline Aloof Personality $(\leq 3.25)$ & 3.33 & 3.92 \\
\hline Pragmatic language deficits $(\leq 2.75)$ & 3.00 & 2.83 \\
\hline Rigid personality $(\leq 3.50)$ & 3.50 & 3.75 \\
\hline Total score $(\leq 3.15)$ & 3.28 & 3.50 \\
\hline
\end{tabular}

Symptom Checklist-90 


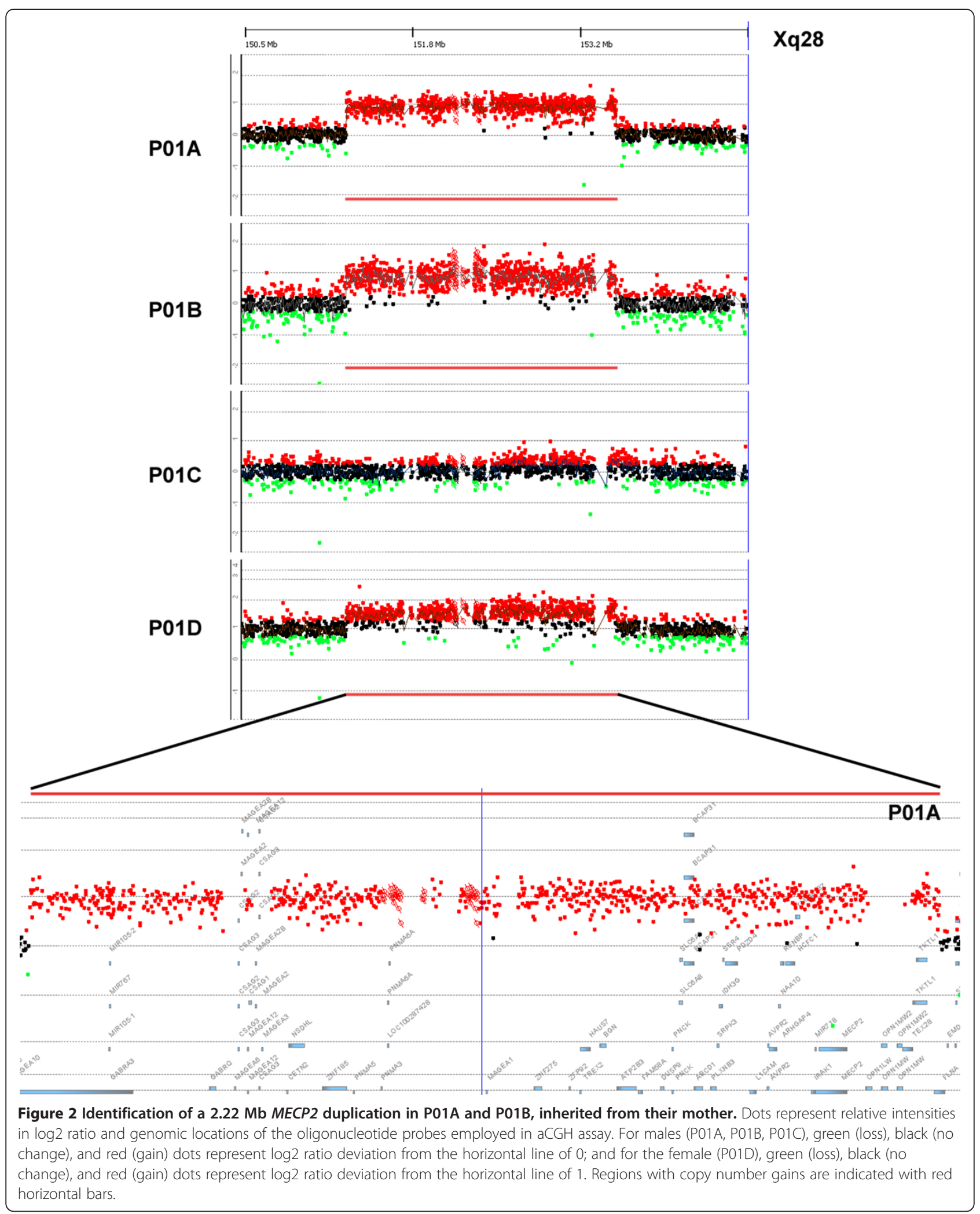


As shown in Figure 2 and Additional file 2, this region contained 54 genes, including two subunits of the GABA receptor $(G A B R A 3, G A B R Q)$, an isocitrate dehydrogenase $(I D H 3 G)$, interleukin-1 receptor-associated kinase 1 (IRAK1), the L1 cell adhesion molecule (L1CAM), a PDZ domain protein (PDZD4), Plexin B3 (PLXNB3) and a creatine transporter (SLC6A8) (More details below). Estimation of the association level of this group of genes with autism was carried out using the AutismKB database (http://autismkb.cbi.pku.edu.cn/index.php), an online database that assigned a weighted score to each gene, $\mathrm{CNV}$ or linkage region reported to be associated with autism, based on published literature [46]. Using this database, we found that although MECP2 was by far the gene most associated with autism, with a high score of 26 , many other genes in the interval also contributed from 3 to 12 points, bringing the score of the entire duplicated region to a very high total of 158 (Additional file 2). The result of this analysis further underscored the importance of this $M E C P 2$-containing region to autism.

\section{Size of duplicated region}

Compared to other patients with reported duplications in $M E C P 2$, the duplicated region of $2.2 \mathrm{Mb}$ identified in family P01 is relatively large. The duplication size in the reported literature is from $0.32 \mathrm{Mb}$ [23] to $2.56 \mathrm{Mb}$ [47]. The centromeric end of the duplication is located in the 3' untranslated region of GABRA3 (located on the complementary strand), suggesting potential duplication of a functional copy of the GABRA3 gene. The telomeric end is within FLNA. Since this gene is also located on the complementary strand, and thus the 5' end and promoter regions are outside of the duplicated region, it is likely that there is no gain-of-function of FLNA. Consistently, the patients did not exhibit the severe, chronic intestinal peudo-obstruction phenotype associated with FLNA duplication [14]. Also worth noting, the telomeric breakpoint is within the $215 \mathrm{~kb}$ region distal to $M E C P 2$ that has been previously identified as a genomic interval prone to rearrangements resulting in MECP2 duplications [47].

Although a number of genes in the duplication region have been reported to be associated with autism, the clinical characteristics of our patients fit well with patients carrying just MECP2 duplication [15,20,23,47], the most autism-related gene within the region. IRAK1, the gene neighboring $M E C P 2$ and also included in the minimum duplication region $[15,20,23,47]$, is a member of the toll-like receptor-signaling pathway [48] and has been proposed to contribute to the recurrent infection phenotype in affected boys [26]. Interestingly, although P01A and P01B had Xq28 duplications that clearly included IRAK1, they did not have the recurrent infections reported in some other patients.
Another gene in the duplicated interval with developmental phenotypes is SLC6A8, a creatine transporter whose loss of function resulted in severe intellectual disability and autism $[49,50]$. In other $M E C P 2$ duplication patients, where the duplicated region also included $S L C 6 A 8$, creatine levels in spinal fluid and urine were normal, and there were no additional phenotypes [20]. Similarly, our patients did not report any metabolic deficiencies.

The other genes in the duplicated interval reported to be associated with autism are mostly based on CNV studies, rare mutations found during X-chromosome sequencing and/or expression studies (see scores in Additional file 2 and references within the AutismKB database). Since there are no detailed patient descriptions in these large scale studies, it is difficult to establish genotype-phenotype relationships for these genes. It is possible that some of these genes may affect the patient's clinical characteristics in the background of $M E C P 2$ duplication. Of particular interest in this group are GABA receptor subunits GABRA3 and GABRQ, components of GABAergic neurotransmission. GABA is the main inhibitory neurotransmitter in the brain, and alterations of GABAergic signaling are thought to be associated with ASD [51]. Also of interest are synaptic components and cell adhesion molecules, which have recently been associated with autism [52]. Duplicated genes in this category include: $L 1 C A M$, encoding the $\mathrm{L} 1$ cell adhesion molecule; PDZD4, the PDZ domain containing and potential post-synaptic scaffold protein, and PLXNB3, the axon guidance molecule Plexin B3, which acts as a receptor for the Semaphorin 5A signal.

\section{Clinical features of boys with duplicated MECP2}

Our results are consistent with previous reports showing lack of correlation between duplication size and clinical phenotypes, as the patients we identified are no more severe than those with much smaller duplications $[14,15,23,26,27,47]$.

\section{Conclusions}

In this study, we identified a Chinese Han family with two brothers carrying a MECP2-containing duplication inherited from their mother. The duplicated region, as defined by microarray analysis, was $2.22 \mathrm{Mb}$ in size. To our knowledge, this is the first report of Chinese Han autistic patients with MECP2 duplication. These individuals shared many characteristics with previously reported MECP2 duplication patients [9-27], including autism, intellectual disability, hypotonia and mild dysmorphic features, but not recurrent respiratory infections or epilepsy. Identification and characterization of more patients are needed for studies regarding potential differences in 
phenotype between ethnic groups, as well as for the correlation between duplication size and clinical phenotype. Importantly, our results demonstrate that $M E C P 2$ duplication is present in autism patients of Chinese Han ethnicity, likely at an occurrence rate suitable for genetic testing.

\section{Consent}

This study was approved by the Ethics Committee of the Children's Hospital of Fudan University (Approval number: Children's Hospital of Fudan University Ethics Protocol 2011-040; Title: Research on the behavioral phenotype and genetic basis of autism spectrum disorder). Written informed consent for the collection of peripheral blood samples and subsequent analyses was obtained from all participating families, with the parents giving consent for themselves and on behalf of their minor children. A copy of the written consent is available for review by the Editor-in-Chief of this Journal.

\section{Additional files}

Additional file 1: Supplemental Methods Measuring MECP2containing CNVs Using AccuCopy Kit. Real-time qPCR. Agilent 1M CGH and data analysis.

Additional file 2: Table S1 Genes in Xq28 duplicated in P01A and P01B, listed together with their AutismKB scores.

\section{Competing interests}

The authors declare no competing financial interests.

\section{Author contributions}

$X X, Z Q$ and $X Y$ conceived the study and participated in its design and coordination; $X X, Q X, Y Z, B W, Y D$, and PL identified the patients and carried out the clinical characterizations; $X Z, T C, J Z$, and $M Z$ carried out the molecular genetics studies; $X Y$ wrote the manuscript; all authors read and approved the final manuscript.

\section{Acknowledgements}

We thank all the children and their families for participating in this study, and thank Ms. Congxiao Yu (Wenmiao Kindergarten, Shanghai) for support in organizing the control subjects for the CGH analysis of this study. We thank Dr. Feng Zhang from Fudan University for advice on CNV analysis. This study was supported by 973 grant 2011CBA00400 from the Ministry of Science and Technology (to XX, ZQ, and XY), grants 31021063 and 31125015 from the National Science Foundation of China (to XY), the Hundred Talent Program from the Chinese Academy of Sciences (to ZQ), and grants GWDTR201220 and 12GWZX0301 from the Shanghai Municipal Health Bureau (to XX).

\section{Author details}

'Department of Child Healthcare, Children's Hospital of Fudan University, Shanghai, China. ${ }^{2}$ Institute of Neuroscience and State Key Laboratory of Neuroscience, Shanghai Institutes for Biological Sciences, Chinese Academy of Sciences, Shanghai, China. ${ }^{3}$ Graduate School of the Chinese Academy of Sciences, Shanghai, China.

Received: 20 June 2012 Accepted: 15 August 2012 Published: 21 August 2012

\section{References}

1. Abrahams BS, Geschwind DH: Advances in autism genetics: on the threshold of a new neurobiology. Nat Rev Genet 2008, 9(5):341-355.

2. Folstein SE, Rosen-Sheidley B: Genetics of autism: complex aetiology for a heterogeneous disorder. Nat Rev Genet 2001, 2(12):943-955.
3. Freitag CM: The genetics of autistic disorders and its clinical relevance: a review of the literature. Mol Psychiatry 2007, 12(1):2-22.

4. Toro R, Konyukh M, Delorme R, Leblond C, Chaste P, Fauchereau F, Coleman M, Leboyer M, Gillberg C, Bourgeron T: Key role for gene dosage and synaptic homeostasis in autism spectrum disorders. Trends Genet 2010, 26(8):363-372.

5. Cooper GM, Coe BP, Girirajan S, Rosenfeld JA, Vu TH, Baker C, Williams C, Stalker $\mathrm{H}$, Hamid R, Hannig V, et al: A copy number variation morbidity map of developmental delay. Nat Genet 2011, 43(9):838-846.

6. Rett A: Cerebral atrophy associated with hyperammonaemia. In Handbook of Clinical Neurology. 29th edition. Edited by Vinken PJ, Bruyn GW. Amsterdam: Elsevier; 1977:305-329.

7. Amir RE, Van den Veyver IB, Wan M, Tran CQ, Francke U, Zoghbi HY: Rett syndrome is caused by mutations in X-linked MECP2, encoding methylCpG-binding protein 2. Nat Genet 1999, 23(2):185-188.

8. Moretti P, Zoghbi HY: MeCP2 dysfunction in Rett syndrome and related disorders. Curr Opin Genet Dev 2006, 16(3):276-281.

9. Nomura Y: Early behavior characteristics and sleep disturbance in Rett syndrome. Brain Dev 2005, 27(Suppl 1):S35-S42.

10. Belligni EF, Palmer RW, Hennekam RC: MECP2 duplication in a patient with congenital central hypoventilation. Am J Med Genet A 2010, 152A(6):1591-1593.

11. Breman AM, Ramocki MB, Kang SH, Williams M, Freedenberg D, Patel A, Bader PI, Cheung SW: MECP2 duplications in six patients with complex sex chromosome rearrangements. Eur J Hum Genet 2010, 19(4):409-415.

12. Budisteanu M, Papuc SM, Tutulan-Cunita A, Budisteanu B, Arghir A: Novel clinical finding in MECP2 duplication syndrome. Eur Child AdolesC Psychiatry 2011, 20(7):373-375.

13. Campos M Jr, Churchman SM, Santos-Reboucas CB, Ponchel F, Pimentel MM: High frequency of nonrecurrent MECP2 duplications among Brazilian males with mental retardation. J Mol Neurosci 2010, 41(1):105-109.

14. Clayton-Smith J, Walters S, Hobson E, Burkitt-Wright E, Smith R, Toutain A, Amiel J, Lyonnet S, Mansour S, Fitzpatrick D, et al: Xq28 duplication presenting with intestinal and bladder dysfunction and a distinctive facial appearance. Eur J Hum Genet 2009, 17(4):434-443.

15. del Gaudio D, Fang P, Scaglia F, Ward PA, Craigen WJ, Glaze DG, Neul JL, Patel A, Lee JA, Irons M, et al: Increased MECP2 gene copy number as the result of genomic duplication in neurodevelopmentally delayed males. Genet Med 2006, 8(12):784-792.

16. Echenne B, Roubertie A, Lugtenberg D, Kleefstra $T$, Hamel BC, Van Bokhoven $H$, Lacombe D, Philippe C, Jonveaux P, de Brouwer AP: Neurologic aspects of MECP2 gene duplication in male patients. Pediatr Neurol 2009, 41(3):187-191.

17. Friez MJ, Jones JR, Clarkson K, Lubs H, Abuelo D, Bier JA, Pai S, Simensen R, Williams C, Giampietro PF, et al: Recurrent infections, hypotonia, and mental retardation caused by duplication of MECP2 and adjacent region in Xq28. Pediatrics 2006, 118(6):e1687-e1695.

18. Kirk EP, Malaty-Brevaud V, Martini N, Lacoste C, Levy N, Maclean K, Davies L, Philip N, Badens C: The clinical variability of the MECP2 duplication syndrome: description of two families with duplications excluding L1CAM and FLNA. Clin Genet 2009, 75(3):301-303.

19. Lugtenberg D, de Brouwer AP, Kleefstra T, Oudakker AR, Frints SG, Schrander-Stumpel CT, Fryns JP, Jensen LR, Chelly J, Moraine C, et al: Chromosomal copy number changes in patients with non-syndromic X linked mental retardation detected by array CGH. J Med Genet 2006, 43(4):362-370

20. Lugtenberg D, Kleefstra T, Oudakker AR, Nillesen WM, Yntema HG, Tzschach A, Raynaud M, Rating D, Journel H, Chelly J, et al: Structural variation in Xq28: MECP2 duplications in $1 \%$ of patients with unexplained XLMR and in $2 \%$ of male patients with severe encephalopathy. Eur J Hum Genet 2009, 17(4):444-453.

21. Meins M, Lehmann J, Gerresheim F, Herchenbach J, Hagedorn M, Hameister K, Epplen JT: Submicroscopic duplication in Xq28 causes increased expression of the MECP2 gene in a boy with severe mental retardation and features of Rett syndrome. J Med Genet 2005, 42(2):e12.

22. Prescott TE, Rodningen OK, Bjornstad A, Stray-Pedersen A: Two brothers with a microduplication including the MECP2 gene: rapid head growth in infancy and resolution of susceptibility to infection. Clin Dysmorphol 2009, 18(2):78-82.

23. Ramocki MB, Peters SU, Tavyev YJ, Zhang F, Carvalho CM, Schaaf CP, Richman R, Fang P, Glaze DG, Lupski JR, et al: Autism and other 
neuropsychiatric symptoms are prevalent in individuals with MeCP2 duplication syndrome. Ann Neurol 2009, 66(6):771-782

24. Reardon W, Donoghue V, Murphy AM, King MD, Mayne PD, Horn N, Birk Moller L: Progressive cerebellar degenerative changes in the severe mental retardation syndrome caused by duplication of MECP2 and adjacent loci on Xq28. Eur J Pediatr 2010, 169(8):941-949.

25. Sanlaville D, Prieur M, de Blois MC, Genevieve D, Lapierre JM, Ozilou C, Pica M, Gosset P, Morichon-Delvallez N, Munnich A, et al: Functional disomy of the Xq28 chromosome region. Eur J Hum Genet 2005, 13(5):579-585.

26. Smyk M, Obersztyn E, Nowakowska B, Nawara M, Cheung SW, Mazurczak T, Stankiewicz P, Bocian E: Different-sized duplications of Xq28, including $M E C P 2$, in three males with mental retardation, absent or delayed speech, and recurrent infections. Am J Med Genet B Neuropsychiatr Genet 2008, 147B(6):799-806

27. Van Esch $H$, Bauters $M$, Ignatius J, Jansen M, Raynaud M, Hollanders $K$, Lugtenberg $D$, Bienvenu $T$, Jensen $L R, G e c z J$, et al: Duplication of the MECP2 region is a frequent cause of severe mental retardation and progressive neurological symptoms in males. Am J Hum Genet 2005, 77(3):442-453.

28. Velinov M, Novelli A, Gu H, Fenko M, Dolzhanskaya N, Bernardini L, Capalbo A, Dallapiccola B, Jenkins EC, Brown WT: De-novo 2.15 Mb terminal Xq duplication involving MECP2 but not L1CAM gene in a male patient with mental retardation. Clin Dysmorphol 2009, 18(1):9-12.

29. Ramocki MB, Tavyev YJ, Peters SU: The MECP2 duplication syndrome. Am J Med Genet A 2010, 152A(5):1079-1088.

30. Chen RZ, Akbarian S, Tudor M, Jaenisch R: Deficiency of methyl-CpG binding protein-2 in CNS neurons results in a Rett-like phenotype in mice. Nat Genet 2001, 27(3):327-331.

31. Collins AL, Levenson JM, Vilaythong AP, Richman R, Armstrong DL, Noebels JL, David Sweatt J, Zoghbi HY: Mild overexpression of MeCP2 causes a progressive neurological disorder in mice. Hum Mol Genet 2004, 13(21):2679-2689.

32. Guy J, Hendrich B, Holmes M, Martin JE, Bird A: A mouse Mecp2-null mutation causes neurological symptoms that mimic Rett syndrome. Nat Genet 2001, 27(3):322-326.

33. Luikenhuis S, Giacometti E, Beard CF, Jaenisch R: Expression of MeCP2 in postmitotic neurons rescues Rett syndrome in mice. Proc Natl Acad Sci USA 2004, 101(16):6033-6038.

34. Shahbazian M, Young J, Yuva-Paylor L, Spencer C, Antalffy B, Noebels J, Armstrong D, Paylor R, Zoghbi H: Mice with truncated MeCP2 recapitulate many Rett syndrome features and display hyperacetylation of histone H3. Neuron 2002, 35(2):243-254.

35. Xi CY, Lu Y, Tan YH, Hua TY, Zhao YJ, Liu XM, Gao H: Analysis of MECP2 gene copy number in boys with autism. J Child Neurol 2011, 26(5):570-573.

36. Du R, Lu C, Jiang Z, Li S, Ma R, An H, Xu M, An Y, Xia Y, Jin L, et al: Efficient typing of copy number variations in a segmental duplication-mediated rearrangement hotspot using multiplex competitive amplification. J Hum Genet 2012, doi:10.1038/ jhg.2012.66.

37. Bailey A, Le Couteur A, Gottesman I, Bolton P, Simonoff E, Yuzda E, Rutter M: Autism as a strongly genetic disorder: evidence from a British twin study. Psychol Med 1995, 25(1):63-77.

38. Association AP: Diagnostic and Statistical Manual of Mental Disorders. Washington, DC: American Psychiatric Association; 1994.

39. Lord C, Rutter M, DiLavore PC, Risi S: Austism Diagnostic Observation Schedule. Los Angeles, CA: Western Psychological Corporation; 1999

40. Derogatis LR, Lipman RS, Covi L: SCL-90: an outpatient psychiatric rating scale-preliminary report. Psychopharmacol Bull 1973, 9(1):13-28.

41. Wang Z-Y: Symptom Checklist 90 (SCL90) in Chinese. Shanghai Archives of Psychiatry 1984, 02:68-70.

42. Gong YS: Wechsler Adult Intelligence Scale - Revised, in Chinese. Changsha: HNDTCBS; 1992.

43. Wechsler D: Wechsler Adult Intelligence Scale - Revised. San Antonio, TX: Pscyhological Corporation; 1981.

44. Hurley RS, Losh M, Parlier M, Reznick JS, Piven J: The broad autism phenotype questionnaire. J Autism Dev Disord 2007, 37(9):1679-1690.

45. Bucan M, Abrahams BS, Wang K, Glessner JT, Herman El, Sonnenblick LI, Alvarez Retuerto Al, Imielinski M, Hadley D, Bradfield JP, et al: Genome-wide analyses of exonic copy number variants in a family-based study point to novel autism susceptibility genes. PLoS Genet 2009, 5(6):e1000536.
46. Xu LM, Li JR, Huang $Y$, Zhao M, Tang $X$, Wei L: AutismKB: an evidence-based knowledgebase of autism genetics. Nucleic Acids Res 2012, 40(Database issue):D1016-1022.

47. Carvalho CM, Zhang F, Liu P, Patel A, Sahoo T, Bacino CA, Shaw C, Peacock S, Pursley A, Tavyev YJ, et al: Complex rearrangements in patients with duplications of MECP2 can occur by fork stalling and template switching. Hum Mol Genet 2009, 18(12):2188-2203.

48. Gottipati S, Rao NL, Fung-Leung WP: IRAK1: a critical signaling mediator of innate immunity. Cell Signal 2008, 20(2):269-276.

49. Newmeyer A, de Grauw T, Clark J, Chuck G, Salomons G: Screening of male patients with autism spectrum disorder for creatine transporter deficiency. Neuropediatrics 2007, 38(6):310-312.

50. Poo-Arguelles P, Arias A, Vilaseca MA, Ribes A, Artuch R, Sans-Fito A, Moreno A, Jakobs C, Salomons G: X-Linked creatine transporter deficiency in two patients with severe mental retardation and autism. J Inherit Metab Dis 2006, 29(1):220-223.

51. Pizzarelli $R$, Cherubini E: Alterations of GABAergic signaling in autism spectrum disorders. Neural Plast 2011, 2011:297153.

52. Zoghbi HY, Bear MF: Synaptic dysfunction in neurodevelopmental disorders associated with autism and intellectual disabilities. Cold Spring Harb Perspect Biol 2012, 4:3

doi:10.1186/1471-2350-13-75

Cite this article as: Xu et al:: A case report of Chinese brothers with inherited MECP2-containing duplication: autism and intellectual disability, but not seizures or respiratory infections. BMC Medical Genetics 2012 13:75.

\section{Submit your next manuscript to BioMed Central and take full advantage of:}

- Convenient online submission

- Thorough peer review

- No space constraints or color figure charges

- Immediate publication on acceptance

- Inclusion in PubMed, CAS, Scopus and Google Scholar

- Research which is freely available for redistribution 